\title{
Fred R. T. Nelson and Carlyn Taliaferro Blauwelt: A manual of orthopaedic terminology (Seventh Edition)
}

\author{
MOSBY Elsevier, 2007, 466 pp.; number illustration; softcover, 63.00 US\$, \\ ISBN: 978-03-2304503-2, ISBN-10: 0-323-04503-0
}

\author{
Pierre Kehr
}

Received: 28 February 2010 / Accepted: 1 March 2010 / Published online: 13 March 2010

(C) Springer-Verlag 2010

This seventh orthopaedic edition of terminology is a true bible of the American orthopaedic vocabulary. After a first work dictionary 30 years ago, the authors wanted by this new edition to update the medical terminology by taking account of the recent discoveries.

The work contains thirteen chapters which embrace the whole of the activities of orthopaedics and traumatology and which contains all the terms:

- Classifications of the fractures

- Diseases of the musculo-skeletal apparatus

- Techniques of the imagery

- Diagnostic tests and operations

- Tests of laboratory

- Plasters, splints, bindings, continuous extensions

- Prostheses and ortheses

- Surgical anatomy and accesses
- Spine

- Hand and wrist

- Foot and ankle

- Physical therapy and readjustment

- Research tasks

An appendix contains the abbreviations in orthopaedics, the plans in anatomy and radiology, the joints motion, the anatomical terms related to orthopaedics. Follows then an interesting etymological chapter, chapters of proper names of diseases, bibliographical references and advised readings. The work ends in an alphabetical index facilitating the entries.

This book must be in the library of any author of articles written in English and also will be very appreciated by all the translators and interpreters.

No funds were received in support of this study.

P. Kehr $(\square)$

SOTEST, Strasbourg, France

e-mail: kehrpier@aol.com 